\title{
The Business Case for Re-Usable Buildings - Business Models, Systems Diagnosis and Case for Action
}

\author{
Kathryn P. Bourke ${ }^{1}$ and Katherine T. Adams ${ }^{2}$ \\ ${ }^{1}$ Whole Life Ltd, 77 Rickmansworth Road, Watford, WD18 7JB UK, \\ Kathryn.bourke@wholelifeltd.co.uk \\ ${ }^{2}$ Loughborough University, School of Architecture, Building \& Engineering, Ashby Road, \\ Loughborough, Leicestershire, LE1 13TU, UK, k.adams@lboro.ac.uk
}

\begin{abstract}
This paper presents the results of a pathfinder project on re-usable buildings which was part funded by Climate- KIC, supported by the EIT, a body of the European Union. It places reusable buildings in the context of sustainability generally, and specifically within the general theme of circular economy transition. It includes a brief summary of the literature review undertaken, focussing on challenges and benefits to the business case for adoption of reusable buildings.
\end{abstract}

Keywords: Re-Usable, Sustainability, Circular Economy, Business Case, Literature Review.

\section{Introduction}

This paper reports the initial results of a scoping study undertaken with partial funding from the Climate KIC programme, which is supported by the EIT, a body of the European Union. The objective of the study was to test out the possibility of generating a critical mass of client support for re-usable buildings. Re-usable buildings for this study included those that could be adapted in use for same use or for different uses within a circular economy context. The work was undertaken by a consortium led by the London Waste and Recycling Board (LWARB), in partnership with the Sustainable Development Foundation (SDF), the Forum for the Future (FforF), the Alliance of Sustainable Building Products (ASBP) and Whole Life Ltd. (WLL).

The early part of the project involved a literature review. The later part of the project included workshops, which led to a sector routemap for the future development of the market, together with initial business models which might encourage and support the market for reusable buildings and components. This paper is focussed on the challenges and benefits identified for the business case for re-usable buildings and components.

\section{Literature Review Methodology and Scope}

The literature review encompassed searches of academic papers, government and nongovernmental organisation (NGO) publications and industry publications using Web of Science. A key word search was undertaken, using the term 'reusable buildings' in addition to sourcing works known to members of the consortium. The main aim of the literature review was to understand the outcomes of previous work in this area, and to identify the gaps with a focus on the business case. 


\section{Main Findings of the Literature Review}

\subsection{Overview}

There is a perception that the application of circular economy principles to the built environment offers major opportunities, in environmental terms but also in terms of social and economic impacts. The reuse of buildings is gaining more interest; with evidence showing that conversion (from one function to another) is increasing in inner urban areas. The benefits and challenges for commercial re-usable buildings are well defined though not often quantified. There is a clear distinction in the motivations between the different development models (develop to sell, manage or occupy), with owner-occupancy driving a greater interest in adaptability. End-users preferences are for versatile and a refit-ready building that provides fewer disruptions, improved service and better quality of space.

\subsection{Application of Circular Economy within the Building Sector}

There are several industry studies that look at how a circular economy can be applied in the building sector, they mostly describe the different business models that could be applied, together with some of the challenges and opportunities, though they are lacking in actual costs. A few of these studies define what a circular economy in the built environment would look like and the macro-economic benefits (at a region or Country level). At the micro (business level), there is little economic information available within the literature on the financial benefits or
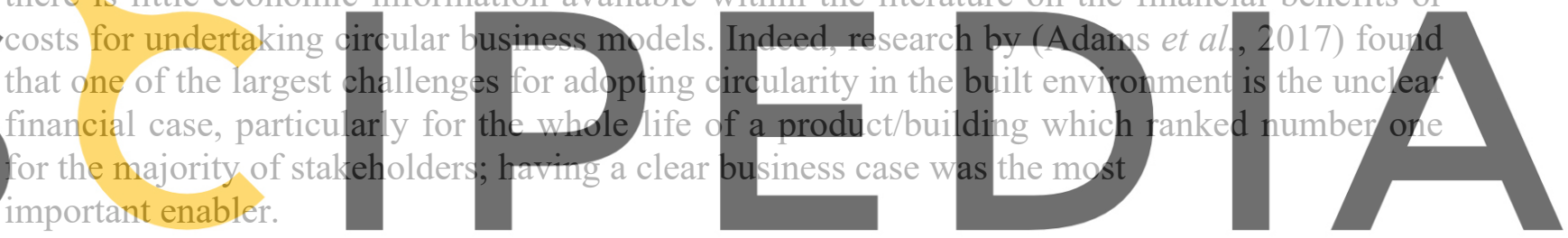

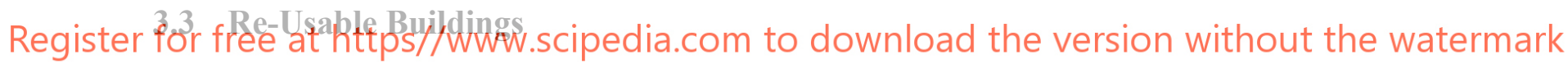
Findings from the review of circular building case studies are limited, but some examples are shown below. They show that the client is instrumental in driving the circular building forward, along with establishing the benefits to the end user.

One of the key drivers identified within the literature is that of obsolescence which affects every building to some degree at some stage during its lifecycle (Douglas, 2006). As buildings age, the rate of decay increases and the decline in building condition escalates unless regular maintenance and upkeep is undertaken. There are 6 principal types of obsolescence; economic, functional, social, legal, physical and aesthetic (Barras and Clark, 1996). As such, when a certain level of obsolescence is reached, a building may require adaptation in some form.

Conversion (changing use or sometimes known as adaptive reuse), is a growing strategy for dealing with vacant buildings such as offices. A study in Liverpool showed that more than $60 \%$ of buildings have changed their original use during their life cycle and around $10 \%$ of them have changed their use frequently (every six years) during the last 20 years thereby signalling an increase in the rate of change (Manewa et al., 2016). However, the property market can be segregated and for example, office investors are not always keen on investing in the housing market. A study of 15 cases in the Netherlands displayed the following success factors: low purchase price, an adaptable floor plan, government subsidy, or clients with long- term 
investment scenarios (housing associations) (Remöy and Voordt, 2014).

\subsubsection{Re-use versus demolition}

There is a debate of the costs of reuse verses demolition and new build, though studies tend to show that it usually lower for the former. For example, it is potentially cheaper to adapt than to demolish and rebuild, in as much as the structural components already exist and the cost of borrowing is reduced, as contract periods are typically shorter (Shipley et al., 2006). This is also likely to be the case if the building is designed for adaptation and re-use.

Buildings are generally demolished because they are perceived to no longer have any value (Kohler and Yang, 2007). In most cases, it is the market that sets this value, even though such an assessment may be based on incomplete information with no consideration given toward externalities. According to Ball (2002), it is generally preferable to repair a building than replace it because the value of the location and quality of a new building is not necessarily better than the old one. In contrast, O'Donnell (2004) suggests that an adapted building will not completely match a new building in terms of operational energy performance, but the shortfall should be balanced against gains in social value. Certainly, the life cycle expectancy of the materials in an older building may well fall short of those in a new building. The age of materials will also directly affect the on-going maintenance costs of an adapted building, which, as a result, may well be higher than those for a new building.

Bullen and Love, 2010 identified that there are a diverse set of issues that organisations need

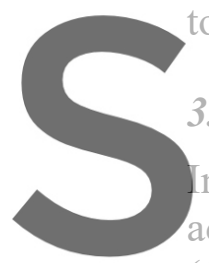

to consider when compar

\subsubsection{Stakeholders}

a survey of high profile

(Gregory, 2004). Workshops undertaken in
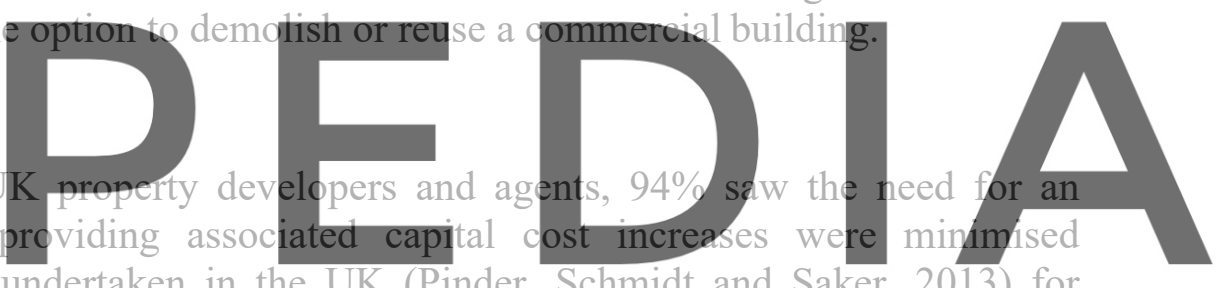

Register adaptability suggested that more adaptable buildings might be suitable investment if they provide easier sales or command a price premium, but there are challenges for speculative developers (those procuring buildings to sell) as the purchaser obtains the benefits of adaptability, not the developer. Owner/occupiers may recoup the benefits through lower rates of depreciation of increased price at sale, but both funders and owners are risk-averse in respect of novel.

\subsubsection{Costs of adaption of existing buildings}

Cost is usually cited in the literature as the main obstacle to developing more adaptable (reusable) buildings, with the assumption being that adaptability results in higher initial construction costs. For example, studies have shown that using solutions such as higher floorto-ceiling heights, system walls and soundproof suspended ceilings, could increase initial construction costs by about 20-25\% (Arge and Landstad, 2002). However, other adaptable design solutions, such as easily divisible building forms and floor plans, were found to be cost neutral (see Figure 2). Other studies found that on average, the design strategies employed resulted in a $1 \%$ increase in initial construction costs when compared with conventional (less adaptable) designs; one-third of the strategies resulted in longer initial construction times.

In the UK the notion that more adaptable (re-useable) buildings cost more to construct has, 
to some extent, been fuelled by past attempts at 'future-proofing' buildings. Guy (1998) explains how, during the 1980s and 1990s, institutional investors' desire to reduce the risk of depreciation associated with changing occupier requirements led to the emergence of an institutional specification that involved over-specifying, among other things, floor loadings, small-power provision and comfort cooling services. Property agents insisted that all new office developments should incorporate these over-specified design features - a case of exchange value prevailing over use value.

Spending more on the initial construction costs of a building to make it more adaptable can only usually be justified if the adaptability is likely to generate some form of benefit or return on investment in the future. Slaughter (2001) estimated that all but one of the adaptable design solutions in her study would pay for themselves at the first adaptation cycle, generating, on average, a net saving equivalent to $2 \%$ of the initial construction cost. She found that threequarters of the adaptable design strategies reduced the time required to adapt the building (thereby reducing disruption to users) and allowed for easier access when maintaining the


Register for free at https//www.scipedia.com to download the version without the watermark

Figure 1. Cost and uncertainty in designing adaptable (re-usable) buildings (Pinder, Schmidt and Saker, 2013)

\subsubsection{Whole life costs}

A critical component to aid re-usable buildings is the use of whole-life costing (WLC), when all the costs and benefits (including incomes) are factored in over the projected lifecycle of the building which includes the cost of the demolished building. WLC can be used as a forecasting tool to evaluate alternative planned capital expenditures with the aim of ensuring the optimum value from capital assets considering all future costs and benefits in present day values.

An example is shown in Figure 2 of the difference in cash flow over the lifecycle of the building based on adaptable and standard design. However, the ultimate answer (for linear and circular buildings) depends on future assumptions which may involve high risk and uncertainty (which are likely to be less in the 'business as usual case' and the hidden costs/benefits associated with social and environmental issues remain untapped.

Discounting is commonly used in WLC and is based on the concept of time preference: the tendency for people to attach more value to a benefit received today than to the same benefit 
received in the future. The choice of discount rate is important in the context of reuse as high discount rates give little weight to more distant entries in the cash flow and place great emphasis on the early years, thus favouring a short-term approach and the minimisation of capital investment. As such it is important to develop an economic model for circular buildings that allows the investor to benefit from day one.

BRE is also looking at how whole life cycle costing can be used within a circular building assessment methodology for the BAMB project. A number of modelling scenarios have been undertaken, and the key findings are that whilst the methodology can show benefits over one lifecycle (through adaptation), taking into account residual value within the current building is difficult, as is applying value from other building cycles. The model (similarly to life cycle assessment), is based on one building, and as such limits the opportunity to transfer value. Discounting as already recognised above, also presents issues (see Lowres and Hobbs, 2017).

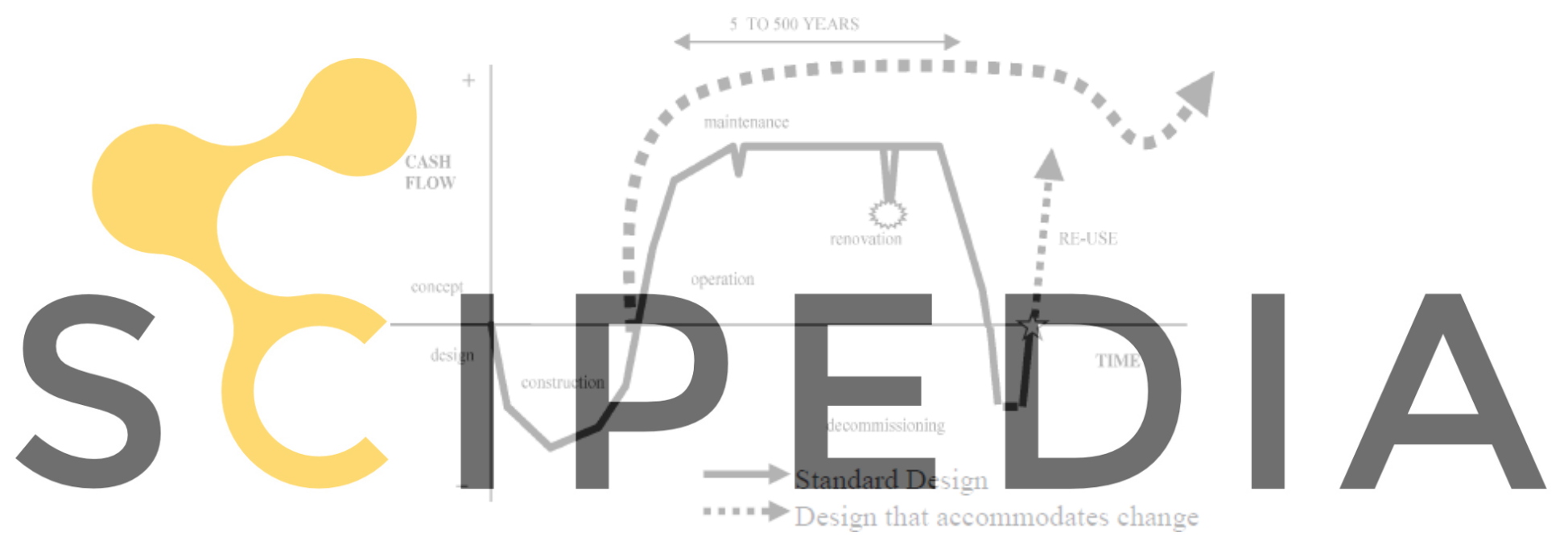

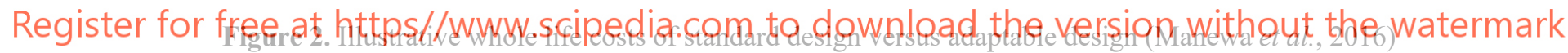

\subsubsection{Financing}

Studies have shown that there is a fundamental shortcoming in the current financing of buildings (Circle Economy and ABN AMRO, 2017). Commonly, a bank issues a loan (mortgage) to buy a building, including the land on which it is built. However, the costs of demolition and recycling (as well as any residual value) at the end of its life are not part of the financing. The result is that it can be cheaper to leave a building vacant or not be incentivised to realise any value from the material within the building. The building and land are viewed as part of the same asset, if these were separated, financing may be easier or at least more flexible. There could be a benefit from having land that is easier to access as buildings can be dismantled quickly and reused elsewhere.

Moving towards circular buildings requires an alliance of parties that collaborate to deliver services. To do so, material reuse has to be the starting point, both during renovation (interior and exterior) and at the end of the lifecycle. This new chain is also based on an integrated 
lifecycle approach to investment decisions and design. The producer or financer remains the owner of the resources and is responsible for the residual value. The residual value of materials remains on the balance sheet and can be estimated using resource model predictions.

Building in such a way that materials have a residual value instead of a negative value (disposal costs) makes investing in circular design useful. The customer pays for the performance of the building or a section of road, instead of the function. This shifts the responsibility for good maintenance and management from the customer to the owner of the materials. Investments in the adaptability of buildings generate value in the long term because the needs of (future) users are more easily met, as such there is value though utility, though there is little empirical evidence to support this within the literature.

Banks such as ABN Ambro are investigating how to allow for higher investment costs which justify lower running costs and a higher final value of the building elements. This therefore means a relatively higher loan-to-value ratio for a project, and a relatively smaller amount of equity capital relative to the loan capital. More (hybrid) financing products can further facilitate the financing. These could be equity, risk funds or other forms of financing besides bank financing. (Circle Economy and ABN AMRO, 2017)

\subsubsection{Valuation}

A building constructed according to a circular method has added value for investors. The value of real estate is currently linked mainly to the price of the location and the difference between rental income and operating costs. Often, the val
secondary importance. This vicw will change fun
circular economy. In addition, the purpose for wh
regularity. A building that can be converted eas
more potential future value than a one-purpose when the current tenant's lease is terminated,
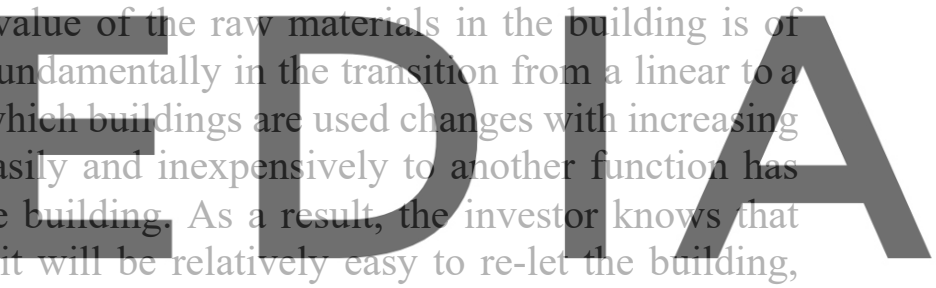

possibly for a different use.

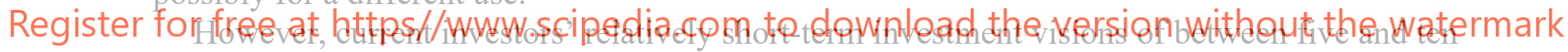

years and the highly limited or total absence of appreciation of this added value by surveyors

often forms a barrier. Research by Elison et al., (2007) suggested that only a very limited interpretation of adaptability, relating primarily to the flexibility of internal spaces, was currently factored into commercial property valuations. Consequently, valuations fail to reflect other forms of adaptability, such as the ability to accommodate changes of use.

McAllister (2009) suggests that property valuations play an important role in the property market by acting as a surrogate for prices, but he also argues that ' $\ldots$ there is some anecdotal evidence to suggest that valuation can act as an impediment to innovation in property markets. This is because property values tend to be based on information from past transactions; in other words, if there is no evidence that a design attribute has added value to a building in the past, then valuers will not ascribe any additional value to those attributes in the present. This can result in a vicious circle, whereby developers will not include a particular design attribute in their buildings because valuers do not consider that it adds value, and valuers do not consider that it adds value because developers do not include it in their buildings.(Pinder, Schmidt and Saker, 2013).

One of the few empirical studies to (inadvertently) provide an insight into the relationship 
between adaptability and rental values was undertaken by Baum (1994). Baum was interested in understanding why some buildings experience higher rates of depreciation than others, so he explored this by statistically analysing the relationship between building characteristics and rental values, using data from 125 office buildings in the City of London. He found that internal configuration (floor to ceiling height and floor layout) and internal specification (quality of finishes and services) were the most important determinants of depreciation in the sample buildings. Baum suggested that because demand for these characteristics would change over time (due to changes in working practices, fashions, etc.) property investors should look to purchase buildings that were flexible, in terms of their configuration and internal specification. He concluded that 'Flexibility reduces the risk of an irreversible and major reduction in the market value of a building'.

\title{
4 Summary of Results of the Literature Review
}

\begin{abstract}
The reuse of buildings is gaining more interest; with evidence showing that conversion (from one function to another) is increasing in inner urban areas. The benefits and challenges for commercial Re-usable buildings are well defined though not often quantified. There is a clear distinction in the motivations between the different development models (develop to sell, manage or occupy), with owner-occupancy driving a greater interest in adaptability. The relative costs of re-use verses demolition and new build remains a matter of debate though studies tend to show that it usually lower for the former.
\end{abstract}

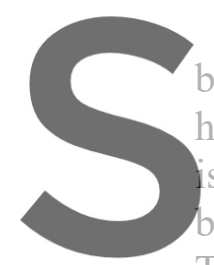

Where building have

buildings can be greater than

higher cost process, whe

usually cited in the iterature as the main obst

buildings, with the assun

Though this is highly dependent on the solur
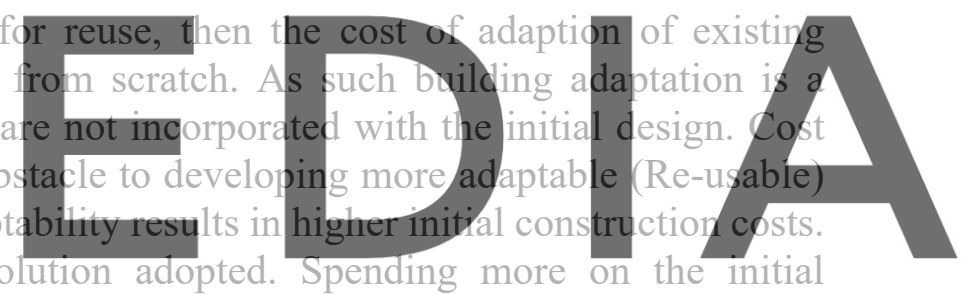

construction costs of a building to make it more adaptable can only usually be justified if the

Register for fref at https//yww scipedia. Eom to dowhload the versign without the watermark

Studies show that adaptable design solutions pay for themselves at the first adaptation cycle,

generating, on average, a net saving equivalent to $2 \%$ of the initial construction cost. Investments in the adaptability of buildings generate value in the long term because the needs of (future) users are more easily met, as such there is value though utility, though there is little empirical evidence to support this within the literature.

Whole life costing is recommended to show payback, however there can be issues in its use from discounting. There is a fundamental shortcoming in the current financing of buildings with the costs of demolition and recycling (as well as any residual value) at the end of its life not factored into business case (a side effect partly of discounting but also reflecting different contractual parties at the end of life). The value of real estate is currently linked mainly to the price of the location and the difference between rental income and operating costs. Often, the value of the raw materials in the building is of secondary importance. It is unclear if property valuations consider any benefits from adaptability and 're-let ability' and how depreciation of assets is factored in. 


\section{ORCID}

Kathryn Bourke:https;//orcid.org/0000-0002-5547-257X

Katherine Adams:https://orcid.org/0000-0002-7757-6396

\section{References}

Arge, K. and Landstad, K. (2002). Generality, Flexibility and Resilience in Buildings: Principles and Properties that Provide Adaptable Office Buildings, Project Report 336, Norwegian Building Research Institute, Oslo.

Adams, K.T. et al. (2017). Circular economy in construction: current awareness, challenges and enablers. ICE Proceedings Waste And Resource Management, 1-11.

Ball, R. (2002). Re-use potential and vacant industrial premises: revisiting the regeneration issue in Stoke-onTrent. Journal of Property Research, 19(2), 93-110.

Barras, R. and Clark, P. (1996). Obsolescence and performance in the central London office market. Journal of Property Valuation \& Investment, 14(4), 63-78.

Baum, A. (1994). Quality and property performance. Journal of Property Valuation \& Investment, 12(1), 31-46.

Bullen, P.A. and Love, P.E.D. (2010). The rhetoric of adaptive reuse or reality of demolition: Views from the field. Cities. Elsevier Ltd, 27(4), 215-224.

Circle Economy and ABN AMRO (2017). A Future Proof Built Environment. Putting circular business models into practice, Amsterdam: CircleEconomy.

Douglas, J. (2006). Building Adaptation, Oxford: Butterworth Heinemann.

Ellison, L., Sayce, S. and Smith, J. (2007). Socially responsible property investment: quantifying the relationship between sustainability and investment property worth. Journal of Property Research 24(3), 191-219.

Gregory, J. (2004). Rehabilitation-new ways for older housing. New South Wales Department of Housing, Retrieved from: www/housing.nsw.gov.au/rehab.htm

Guy, S. (1998). Developing alternatives: energy, offices and the environment. International Journal of Urban and Regional Research, $22(2$

Kohler, N. and Yang, W. $35(4), 351-362$.

Lowres, F. and Hobbs, G. assessment (LCA) app

Manewa, A. et al. (2016
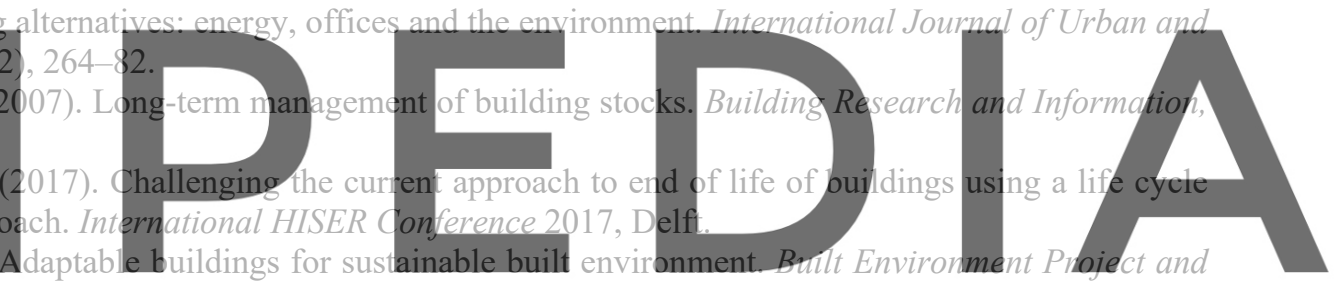
Asset Management, 6(2), 139-158.

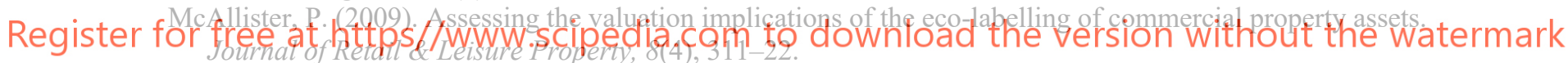

O’Donnell, C (2004). Getting serious about green dollars. Property Australia 18(4), 1- 2. Retrieved from http://www.propertyoz.com.au

Pinder, J., Schmidt, R.I. and Saker, J. (2013). Stakeholder perspectives on developing more adaptable buildings. Construction Management and Economics, 31(5), 440-459.

Remöy, H. and Voordt, T. Van Der. (2014). Adaptive reuse of office buildings into housing : opportunities and risks. Building Research \& Information, 42(3), 381-390.

Shipley, R., Utz, S. and Parsons, M. (2006). Does adaptive reuse pay? A study of the business of building renovation in Ontario, Canada. International Journal of Heritage Studies, 12( 6), 505-520.

Slaughter, S. (2001). Design strategies to increase building flexibility. Building Research \& Information, 29(3), 208-17. 